\title{
Sonoelastografía mamaria, a propósito de cuatro casos
}

\author{
Sotomayor Rivas, Juan Pablo*
}
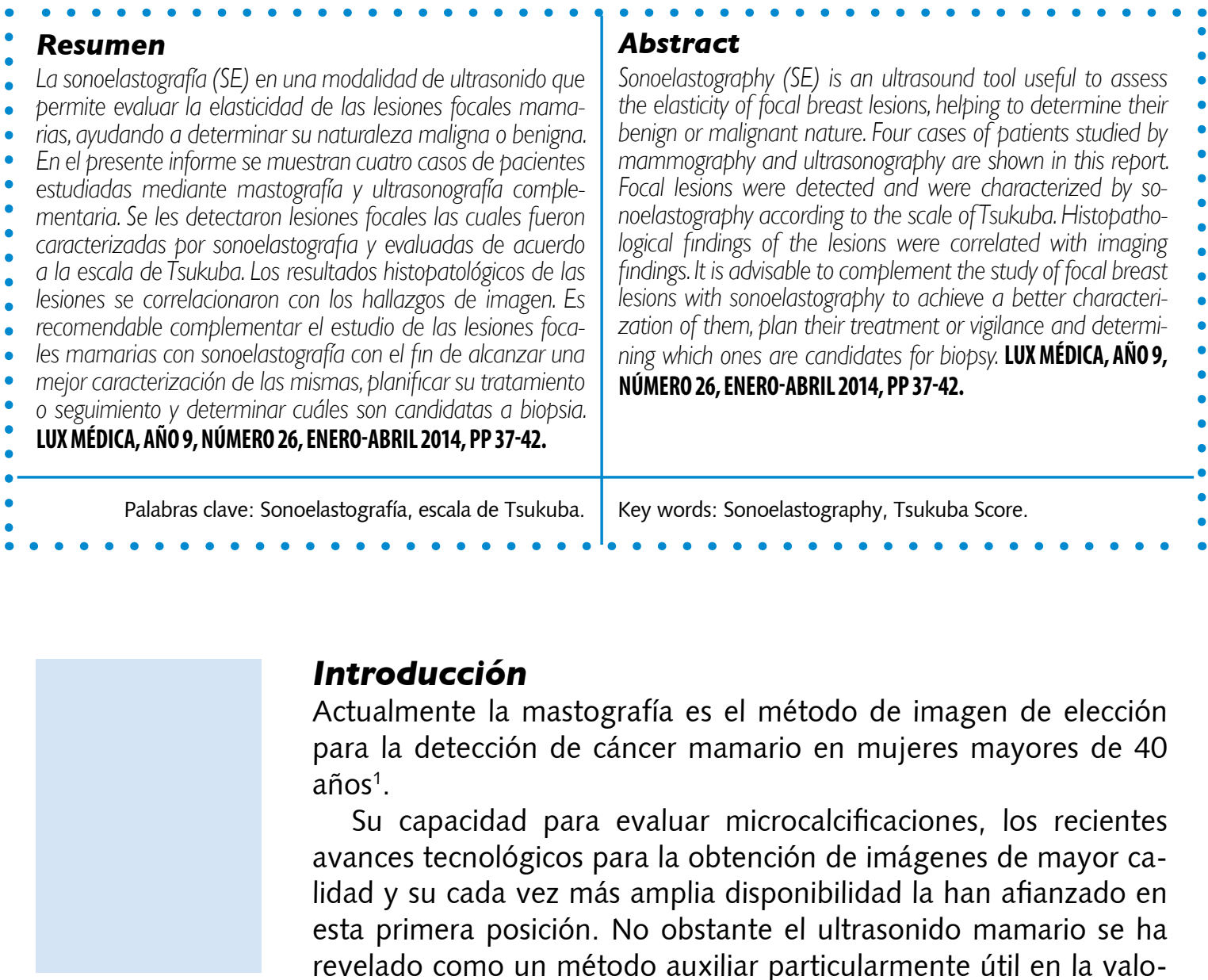

\section{Introducción}

Actualmente la mastografía es el método de imagen de elección para la detección de cáncer mamario en mujeres mayores de 40 años'.

Su capacidad para evaluar microcalcificaciones, los recientes avances tecnológicos para la obtención de imágenes de mayor calidad y su cada vez más amplia disponibilidad la han afianzado en esta primera posición. No obstante el ultrasonido mamario se ha revelado como un método auxiliar particularmente útil en la valo-

Médico Radiólogo, Coordinador del Departamento de Tomografía y Resonancia Magnética en Diagnóstico Médica Integral Siglo XXI

Fecha de recibido: 16 de diciembre 2013

Fecha de aceptación: 10 febrero 2014

Correspondencia: Dr Juan Pablo Sotomayor Rivas. Médico Radiólogo. Coordinador del Departamento de Tomografía y Resonancia Magnética en Diagnóstico Médica Integral Siglo XXI. Emiliano Zapara No 532 Zona Centro CP 20000 Aguascalientes, Ags., México teléfono (449)9102930 extensión 165 Correo electrónico drsotomayor@siglo21.mx 


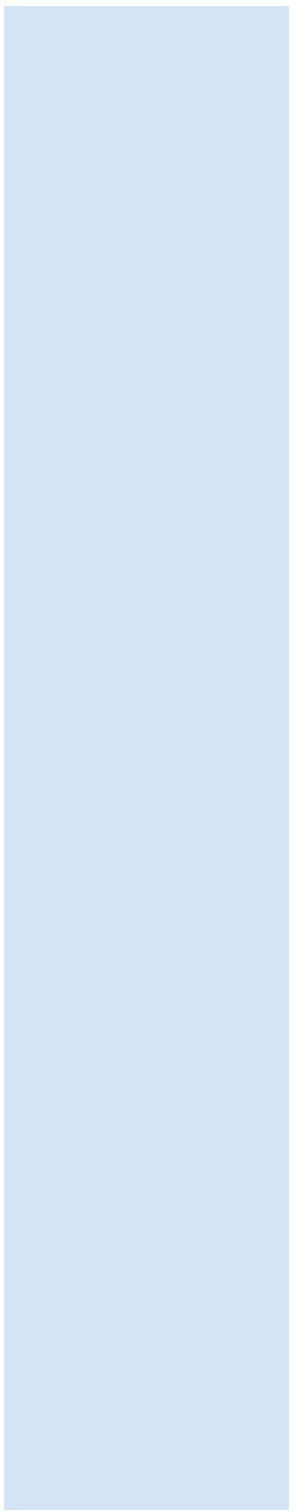

ración de mamas densas, así como en la caracterización de lesiones sólidas y quísticas ${ }^{1,2}$

La sonoelastografia (SE) es una modalidad de ultrasonido que proporciona datos adicionales en la evaluación de lesiones focales mamarias. Su funcionamiento se basa en el hecho de que las lesiones mamarias malignas tienden a ser sólidas e infiltran tejidos adyacentes por lo que alteran la elasticidad del tejido endureciéndolo ${ }^{1-4}$

El primer estudio de SE con aplicación a lesiones mamarias se publicó en 1997 por Garra y colaboradores, demostrando la utilidad de esta herramienta. Posteriormente se estableció la categorización de las lesiones de acuerdo a su patrón en mapa de color conforme a la escala propuesta por Itoh, Ueno y colaboradores. ${ }^{4}$

Esta escala, conocida como de Tsukuba, se correlaciona con el Breast Imaging Report and Database System (BI-RADS, por sus siglas en inglés) permitiendo al clínico decidir el camino terapéutico más conveniente para la paciente, otorgando puntuaciones a las lesiones (Figura 1).

La puntuación 1 corresponde a lesiones elásticas benignas, particularmente del tipo quístico, con BI-RADS II.

La puntuación 2 corresponde a lesiones sólidas pero que conservan elasticidad, como los fibroadenomas, también equivalente a BI-RADS II.

Las lesiones de puntuación 3 manifiestan dureza dominante con áreas centrales de elasticidad remanente, la mayoría de ellas son benignas, sin embargo, dado que estadísticamente hasta un 15\% de lesiones malignas pueden presentar este patrón de comportamiento, se recomienda biopsia para esta categoría, que corresponde a BI-RADS III.

Las puntuaciones 4 y 5 se correlacionan bien con los BI-RADS IV y $V$ respectivamente teniendo en cuenta que se recomienda toma de biopsia en todos los casos y sus probabilidades de malignidad son superiores a $80 \%$. 1,3,4

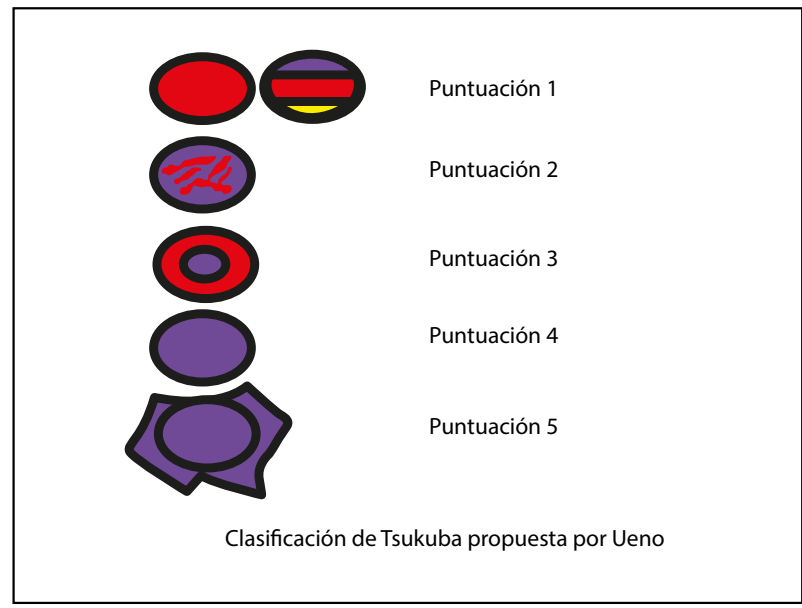

Figura 1. Puntuación de Tsukuba para lesiones focales mamarias en SE. Esta escala fue propuesta por Itoh, Ueno y colaboradores en 2006, actualmente empleada a nivel mundial. La presente escala ha sido modificada de la original en sus colores a fin de coincidir con los mapas cromáticos actuales de los equipos Phillips con los que se realizaron nuestras exploraciones. Los mapas cromáticos pueden variar dependiendo de las diferentes marcas de ultrasonido. 


\section{Presentación del caso clínico}

Primer caso. Femenino de 45 años con antecedentes familiares de carcinoma mamario recién diagnosticado en hermana tres años mayor. Estudio mastográfico previo dos años antes, con categoría BI-RADS II sin lesiones focales. Una mastografía actual muestra mamas tipo II del American College of Radiology (ACR, por sus siglas en inglés). Se identifica imagen de aspecto redondeado sin distorsión del tejido mamario adyacente en cuadrante superointerno de mama derecha. El ultrasonido identifica imagen ovoidea de $6 \times 4 \mathrm{~mm}$, de bordes lisos, con eje mayor paralelo a la piel. Con SE la imagen se confirma sólida y con patrón en mosaico que indica zonas elásticas en su interiorcon puntuación 2 de escala de Tsukuba. Estos datos fueron compatibles con probable fibroadenoma y se otorgó evaluación global de BI-RADS II en ausencia de otros hallazgos. La paciente insistió en realizarse biopsia excisional por decisión propia. El estudio histopatológico confirmó fibroadenoma (Imagen 1).

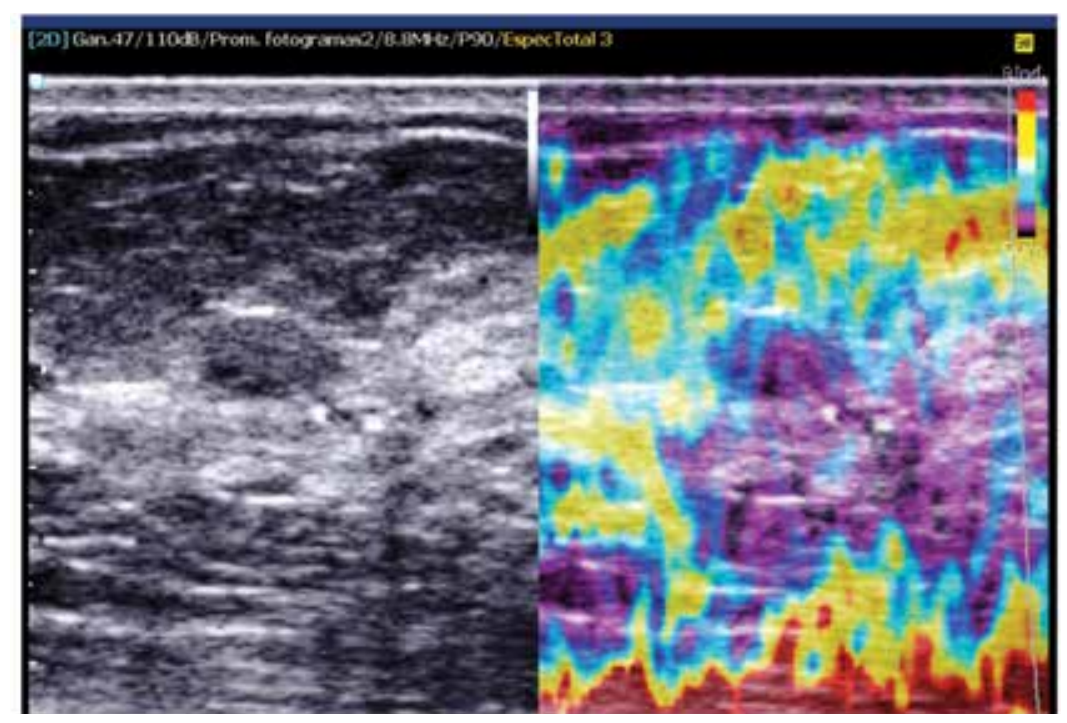

Imagen 1. Comparación entre ultrasonido convencional en escala de grises y SE. El fibroadenoma manifiesta clásico patrón en mosaico.

\section{Segundo caso}

Femenino de 58 años, sin antecedentes patológicos ni heredofamiliares relevantes. Acude por primera vez a mastografía por indicación de su médico quien a la exploración física encontró área indurada a la palpación en el cuadrante supero-externo de la mama izquierda. La paciente refiere haber tenido dolor leve persistente en la mama izquierda al realizar ejercicio (trotar) en los últimos tres meses. Su análisis mastográfico reveló mamas tipo III del ACR con imagen de aspecto nodular en mama izquierda localizada en el cuadrante supero-externo, con bordes lobulados y sin microcalcificaciones. Se le practicó ultraso- 
nido complementario identificándose una zona hipoecoica poco definida, de $10 \mathrm{~mm}$ de diámetro promedio. El análisis con SE confirmó la presencia de una lesión sóli$\mathrm{da}$, rígida, con ausencia de elasticidad en toda la lesión con puntuación 4 de escala de Tsukuba, y evaluación total de BI-RADS IVc, con sospecha de malignidad del 90 al 94\%. El análisis histopatológico reveló carcinoma ductal (Imágenes 2 y 3 ).
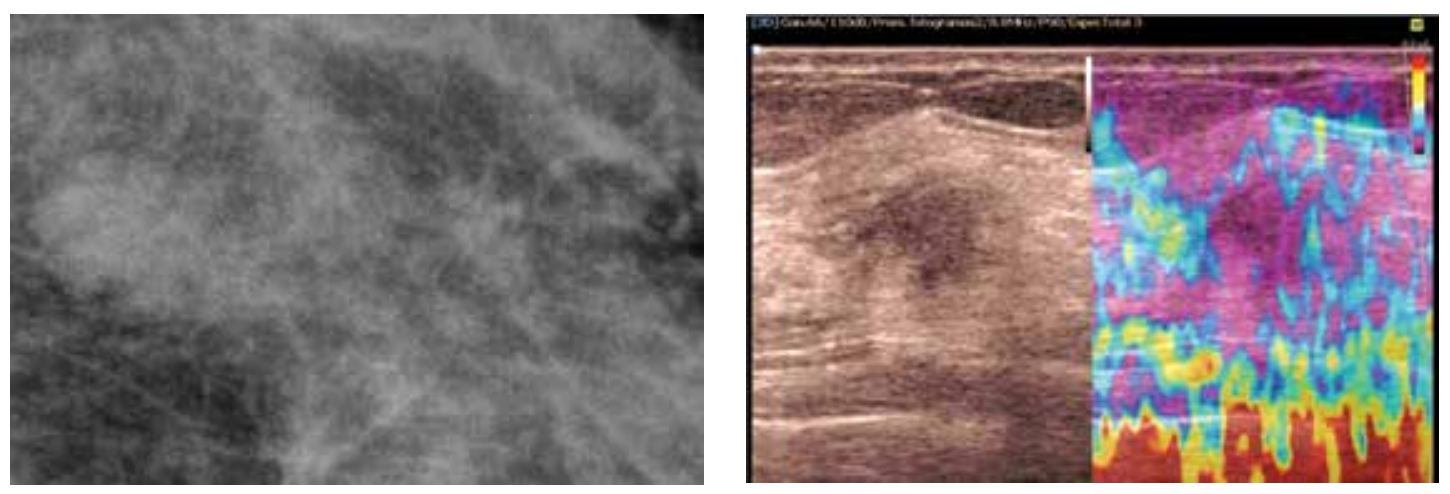

Imágenes 2 y 3. Placa mastográfica y ultrasonido de lesión sospechosa. La SE muestra una lesión que no se modifica durante la exploración debido a su falta de elasticidad.

\section{Tercer caso}

Femenino de 41 años, sin antecedentes de importancia. Asiste a realizarse mastografía por primera vez referida de centro de salud rural. No refiere molestias. Las placas mastográficas ponen de manifiesto un patrón tipo II del $A C R$, con una imagen densa, redondeada en cuadrante supero-externo de mama derecha, con bordes parcialmente ocultos por el tejido mamario residual circundante. (Imágenes 4 y 5). El análisis sonográfico y con SE identificó una lesión sólida, rígida en su mayoría, conservando todavía un área un tanto excéntrica de elasticidad. Debido a su puntuación 3 en escala de Tsukuba y al aspecto lobulado de su contorno se indicó toma de biopsia. El estudio histopatológico concluyó fibroadenoma con metaplasia apocrina.
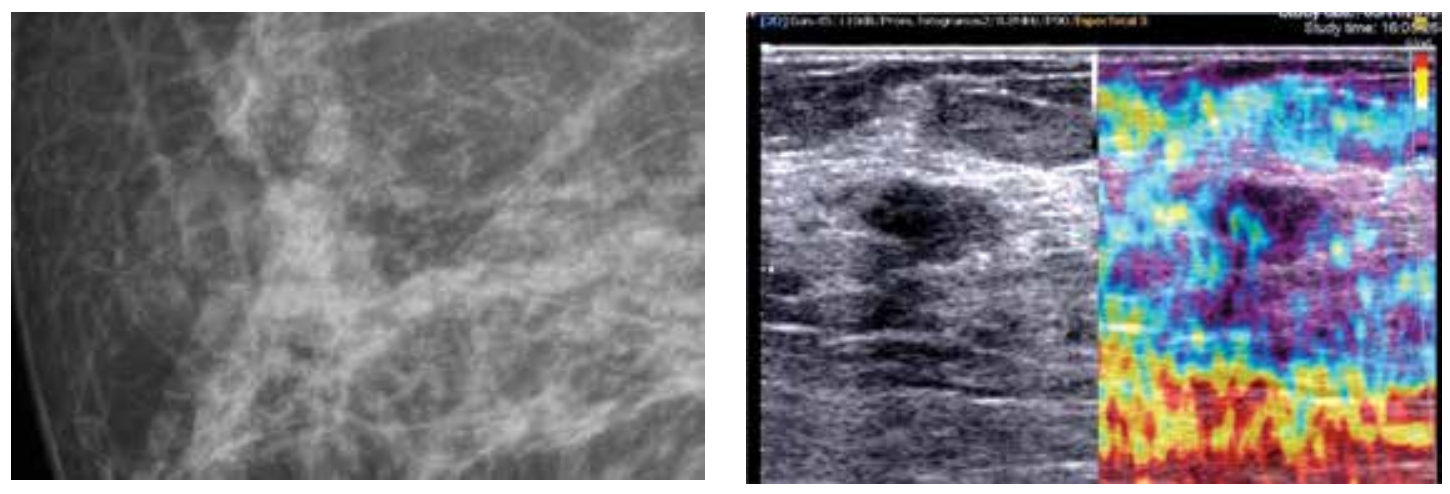

Imágenes 4 y 5. Placa mastográfica muestra imagen densa de bordes parcialmente ocultos. SE muestra una lesión con puntuación 3 de Tsukuba. Teniendo en cuenta este hallazgo la paciente se envió a toma de biopsia. 


\section{Cuarto caso}

Femenino de 43 años, sin antecedentes de importancia. Acude a su revisión anual con resultados previos de BI-RADS II por presencia de quistes de pequeño diámetro. El estudio mastográfico actual con mamas tipo II del ACR. Se identifican numerosas imágenes redondeadas de pequeño diámetro. En estudio sonográfico se identifican lesiones hipoecoicas, de paredes lisas regulares. Se confirma el carácter elástico de las lesiones con puntuación 1 de la escala Tsukuba, correspondientes a quistes simples (Imagen 6).

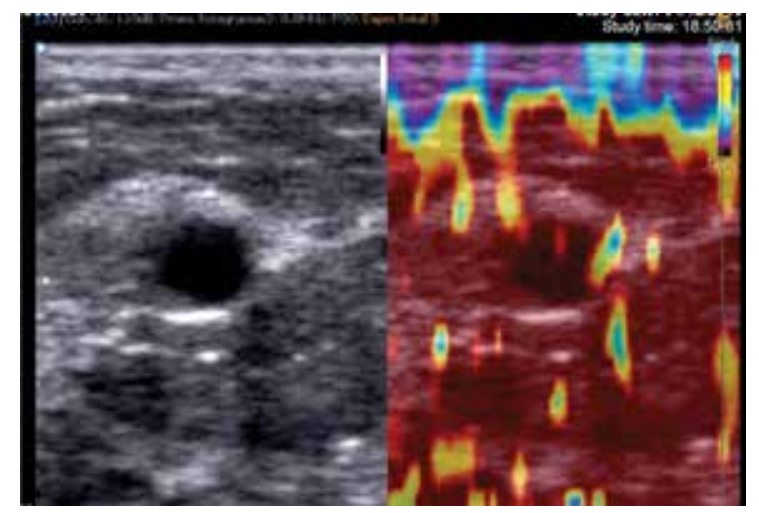

Imagen 6. Lesión elástica con puntuación 1 de Tsukuba, de tipo benigno, compatible con quiste simple.

\section{Discusión}

La detección oportuna de cáncer mamario es un objetivo primario de los programas de salud a nivel mundial debido a su alta prevalencia y elevada mortalidad.

La amplia disponibilidad de la mastografia y su inigualable capacidad para analizar microcalcificaciones la sitúan como el estudio de elección en el cribado de mujeres mayores de 40 años así como en situaciones donde se sospecha la presencia de patología mamaria específica.

Sin embargo, no todas las variedades de carcinoma mamario se acompañan de microcalcificaciones, manifestándose como lesiones focales de comportamiento sólido que deben entonces de ser estudiadas en forma ideal mediante ultrasonido.

La SE complementa los datos aportados por la mastografía, el ultrasonido conven- cional e incluso el Doppler, en la investigación de lesiones focales mamarias.

La puntuación de los mapas cromáticos con la escala de Tsukuba reduce la ambigüedad de criterios al estudiar el comportamiento de las lesiones y sobre todo ayuda a tomar decisiones y despejar incógnitas en relación con las lesiones catalogadas como BI-RADS III. 5,6

Dichas lesiones suelen ser complicadas en su manejo debido a que se sitúan en la frontera entre la benignidad y la malignidad.

Sin embargo, si a un BI-RADS III inicial se le agrega exploración de SE con puntuación 2 de Tsukuba, la lesión tiene alta probabilidad de ser benigna y se puede reconsiderar el BI-RADS a nivel II. En cambio, una lesión con puntuaciones 3 y 4 tiene considerables posibilidades de ser maligna 
y elevaría el BI-RADS III previo a IV, aconsejándose toma de biopsia. ${ }^{5-8}$

En la presente serie de casos se contó con la verificación histopatológica de tres lesiones sólidas, resultando dos de ellos benignos y uno maligno.
En este sentido también cabe apuntar que la SE puede ayudar a reducir un número de biopsias innecesarias de lesiones focales con patrón benigno en esta modalidad de imagen.

\section{Conclusiones}

La SE aumenta la capacidad diagnóstica de las exploraciones de ultrasonido en presencia de lesiones focales mamarias, particularmente las de carácter sólido.

Con base en sus hallazgos es posible aclarar el camino a seguir en lesiones originalmente catalogadas como BI-RADS III y definir cuáles lesiones requieren biopsia y cuáles muestran un patrón de comportamiento benigno.

Sin embargo, no hay que perder de vista que, si bien esta modalidad de ultrasonido muestra grandes bondades, la mastografía con su correcta técnica y adecuada interpretación sigue siendo el gold standard en el diagnóstico temprano del cáncer mamario.

\section{Bibliografía}

1.- De Moya I, Cruz E, García Z. Correlación existente entre los hallazgos detectados en elastografía mamaria y su correspondencia histopatológica. UCE Ciencia. Revista de postgrado, Norteamérica, 1, jun. 2013. Disponible en: http://www.uceciencia.edu. do/index.php/uceciencia/article/view/58.

2.- Gómez V, González M, Ariza R. Elastografía en mama. Imagen Diagnóstica 2010; 1 (2):47-50.

3.- Campos J, Sentis M. Elastosonografía mamaria. Revista Chilena de Radiología 2008; 14 (3): 122-127.

4.- Itoh A, Ueno $E$, Tohno $E$, et al. Breast diseases: clinical applications of US elastography for diagnosis. Radiology 2006; 239:341-350.

5. Schaefer F, Athanasiou A, Leconte I, Salvador R, Ganau $S$, Wallis $M$, Plancher $C$, Tardivon A. Ultrasound elastography: Results of a European multicentric study of 429 breast lesions. European Congress of Radiology 2008

6. Thomas A, Fischer T, Frey $\mathrm{H}$ et al. Real-time elastography-an advanced method of ultrasound: First results in 108 patients with breast lesions. Ultrasound Obstet Gynecol. 2006; 28: 335-340.

7. Ophir J, Kaisar Alam S, Garra Brian S, Kallel Faouzi, Konofagou Elisa E, Krousko Thomas,. Merritt CRB, Righetti Raffaella, Souchon Remi, Srinivasan Seshadri, Varghese Tomy Elastography: Imaging the elastic properties of soft tissues with ultrasound, 2002; 29(4):155-171.

8. Guzmán Aroca $F$, et al. La elastografía: una nueva aplicación de la ecografía. ¿Cuál es su utilidad clínica? Radiología. 2012. http://dx.doi.org/10.1016/j. rx.2012.09.006 